\title{
COMPARISON OF THE SURFACE CONDITIONS OF THE INLAND ICE SHEET, DRONNING MAUD LAND, ANTARCTICA, DERIVED FROM NOAA AVHRR DATA WITH GROUND OBSERVATION
}

by

\author{
Yoshiyuki Fujii, Takashi Yamanouchi
}

(National Institute of Polar Research, Kaga 1-chome, Itabashi-ku, Tokyo 173, Japan)

Kazuya Suzuki

(University of Electro-Communications, Chofugaoka 1-chome, Tokyo 182, Japan)

and

Shinya Tanaka

(Space Systems Department, Fujitsu Ltd, Kamata 1-chome, Ohta-ku, Tokyo 144, Japan)

\section{ABSTRACT}

The surface conditions of the inland ice sheet in east Dronning Maud Land, Antarctica, are derived from the NOAA-7 AVHRR data received at Syowa Station and then compared with the ground observations which were collected in November 1984 along a $243 \mathrm{~km}$ long traverse route at altitudes ranging from 2700 to $3400 \mathrm{~m}$ a.s.l. The variations in the AVHRR data are well related to the distribution of glazed surfaces. The areas with lower albedo, higher surface temperature, lower ratio of channel $2 /$ channel 1 , and lower T4-T5 coincide with the areas where a glazed surface has developed. This result is attributed to the fact that the glazed surface is composed of a multi-layered ice crust and that its radiative and thermal properties are closer to ice than to snow. The present study shows that the NOAA AVHRR data are useful for distinguishing bare ice, glazed surfaces, and snow surfaces of the Antarctic ice sheet.

\section{INTRODUCTION}

Surface conditions of the Antarctic ice sheet show regional characteristics from the coast towards the interior. The area between 1800 and $3200 \mathrm{~m}$ a.s.1., where precipitation is low and the katabatic wind is strong, is characterized by the extensive distribution of a flat, glazed surface with polygonal cracks formed by thermal expansion and contraction of the hard surface (Watanabe 1978). The flat glazed surface is a long-term (more than a few years) accumulation-free surface as identified by Watanabe (1978), and mass loss exceeding $5 \mathrm{~g} \mathrm{~cm}^{-2}$ per year occurs at the surface by sublimation (Fujii and Kusunoki 1982). The determination of the distribution of glazed surfaces is of great importance for the study of the mass and heat balance of the Antarctic ice sheet.

In this paper, the distribution of glazed surfaces observed during an oversnow traverse in November 1984 in the inland plateau of east Dronning Maud Land is compared with the NOAA-7 AVHRR visible and infra-red images. The satellite images used in this paper were received at Syowa Station (lat. $69^{\circ} 00^{\prime}$ S., long. $39^{\circ} 55^{\prime} \mathrm{E}$.) during the period of the oversnow traverse.

\section{GROUND TRUTH}

Surface conditions of the inland ice sheet of east Dronning Maud Land were observed visually from an

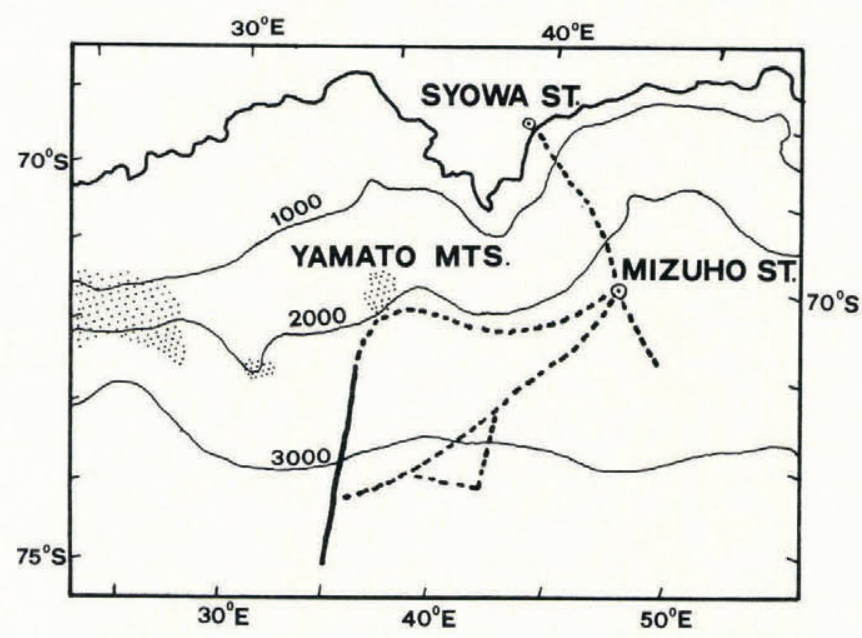

Fig.1. Glaciological traverse route (dashed line) for October to December 1984. The solid line indicates the present study line where surface conditions were derived from both ground and satellite observations.

oversnow vehicle along the traverse route as shown in Fig.1. The oversnow traverse was conducted from October to December 1984 as a part of the 5-year glaciological research programme called East Queen Maud Land Glaciological Program (EQGP) 1982-86.

Surface features are morphologically classified into three categories for the in-situ observations as described below.

Rough surface: composed of sastrugi greater than $30 \mathrm{~cm}$ in height.

Smooth surface: composed of a smooth surface, dune, erosional pit, and/or very small-scale sastrugi (less than $30 \mathrm{~cm}$ in height).

Glazed surface: composed of a multi-layered ice crust as shown in Fig.2.

Each surface feature changes successively; for example, sastrugi, dune, smooth surface, and glazed surface in accordance with the active, inactive, and equilibrium stages in the deposition-erosion process, respectively (Watanabe 


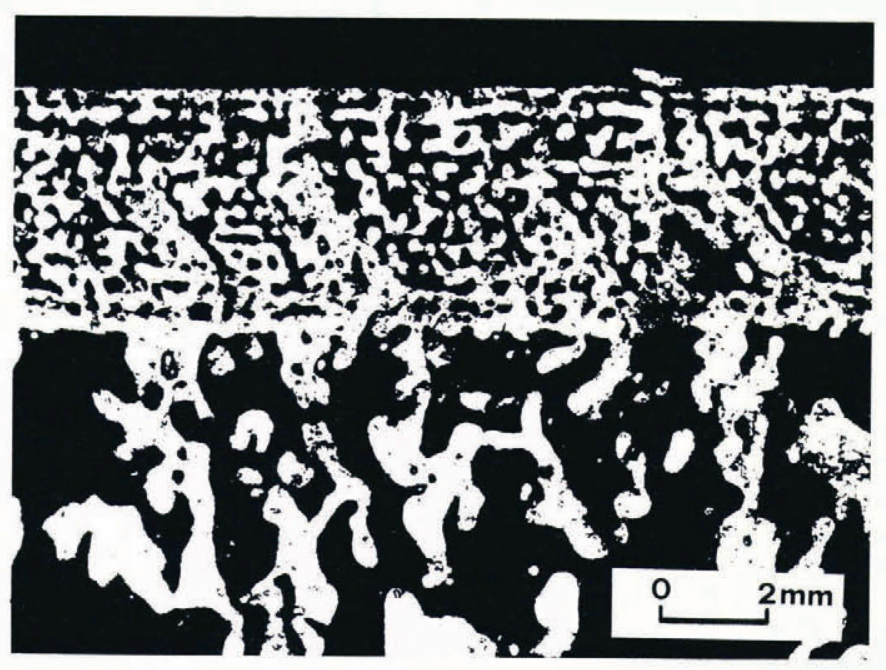

Fig.2. A thin section of a glazed surface with a multi-layered ice crust photographed in crossed polarized light.

1978). However, these stages in the depositional-erosion process may be affected by a large-scale step such as an undulation of the ice-sheet surface, i.e. a glazed surface develops at the relatively steep slope where the katabatic wind accelerates and snow deposition does not occur readily.

As these surfaces of ten co-exist, the areal ratio of each surface was described. The distributional boundaries were recorded with a resolution of $10 \mathrm{~m}$ using the distance meter of an oversnow vehicle, and their locations were interpolated from the positions of the nearest two overnight spots where exact satellite positioning was observed with an accuracy of $\pm 30 \mathrm{~m}$ using a JMR $-4 \mathrm{~A}$ system.

The length of the present study line is $243 \mathrm{~km}$ along long. $35^{\circ} \mathrm{E}$. from the southernmost route station (lat. $75^{\circ} 00^{\prime}$ S., long. $35^{\circ} 01^{\prime}$ E., $3396 \mathrm{~m}$ a.s.l.) to the station located at lat. $72^{\circ} 50^{\prime} \mathrm{S}$., long. $35^{\circ} 09^{\prime} \mathrm{E}$, , and $2692 \mathrm{~m}$ a.s.l. south of the Yamato Mountains (Fig.1). In the illustrations for this paper, the southernmost station is located at $\mathrm{km} 0$.

Fig. 3 shows the observational results on the surface features along the study line, i.e. the glazed surface develops widely with a zonal width of $1 \mathrm{~km}$ to more than $10 \mathrm{~km}$, and is the most predominant surface feature along the study line. The area where the glazed surface predominates amounts to about $45 \%$ of the area along the study line.

\section{NOAA AVHRR DATA}

For the present study, we used NOAA-7 AVHRR data received on 20 and 30 November 1984 when there were no clouds over the study line and the ground observation was carried out.

The AVHRR sensor of NOAA-7 provides imagery in five different spectral bands with a ground resolution of about $1.1 \mathrm{~km}$ at nadir. This ground resolution is comparable to the minimum width of the zonal distribution of the glazed surface. Channel $1 \quad(0.58-0.68 \mu \mathrm{m})$ and channel 2 $(0.725-1.10 \mu \mathrm{m})$ measure radiances of reflected solar

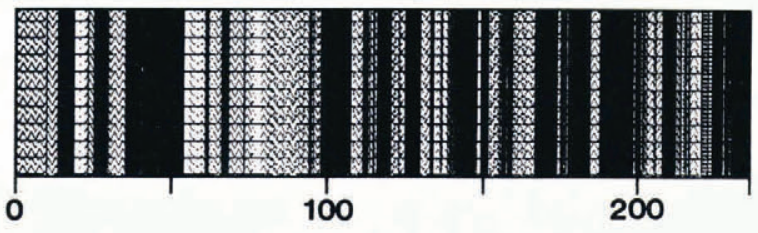

DISTANCE (km)

Fig.3. Distribution of surface features along the study line. Rough and smooth surfaces are illustrated as a wave-like dotted line and lateral stripes. Glazed surfaces are shown as black and darker parts for the features with an areal ratio of more than 70 and $50 \%$, respectively. radiation, and channel $3 \quad(3.55-3.93 \mu \mathrm{m})$, channel 4 $(10.3-11.3 \mu \mathrm{m})$, and channel $5(11.5-12.5 \mu \mathrm{m})$ measure radiances of emitted terrestrial radiation and some minor parts of the reflected solar radiation.

Calibrations and corrections of the map projection were made by affine transformation using the ground-control positions of distinctive features on the bare-ice field near the Sør-Rondane and the Yamato Mountains obtained on 30 November, as shown in Fig.4. The ground-control points

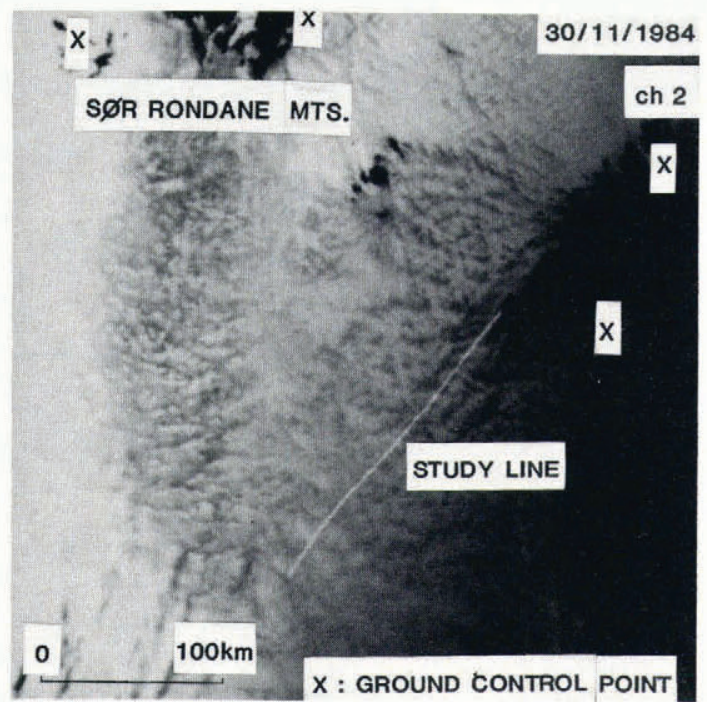

Fig.4. A NOAA-7 AVHRR image of channel 2 along the present study line, $243 \mathrm{~km}$ in length south of the Yamato Mountains.

were identified on the $1: 250000$ scale Landsat-image maps issued by the Geographical Survey Institute of Japan in 1984 and 1985.

Fig.5 shows the data from channels $1,2,4$, and 5 along the study line obtained on both 20 and 30 November. Channel 3 was not used because of noise in the data. Though the absolute values from each channel on both days differ from one another, the variation patterns show a good correlation. This may indicate that the calibrations and corrections of the map projection of the images for both days were made with almost the same accuracy, and these patterns from AVHRR data do not reflect temporal phenomena, such as clouds and drifting snow, but relatively stable surface conditions.

Reflected radiances from channels 1 and 2 decrease with distance because of the decrease in solar altitude with the distance. The spectral albedo depends on the surface conditions and the azimuth angle of the Sun as well as the relative angle between the Sun and the satellite. The albedo of bare ice is lower than that of dry and clean snow in the short-wave bands and is particularly low in the near infrared bands (channel 2) (Warren 1982). Furthermore, the albedo depends on snow grain-size, i.e. it decreases with increasing grain-size of the snow. The dependence of the reflectivity on grain-size is more sensitive in the near infra-red region (channel 2) than in the visible region (channel 1) (Dozier and others 1981). Since the multi-year ice crust of a glazed surface has a higher density $\left(0.69 \mathrm{Mg} \mathrm{m}^{-3}\right.$ ) than a snow surface (Fujii and Kusunoki 1982 ), the grain-size of a glazed surface can be regarded as large compared with that of a snow surface.

Brightness temperatures for channels 4 and 5 along the study line increase with distance, as shown in Fig.5, because of the decrease in altitude of the ice-sheet surface with distance.

\section{DISCUSSION}

The NOAA-7 AVHRR data from the different spectral bands are compared with each other in order to derive the surface conditions, which can then be compared with the 
20 NOV

$30 \mathrm{NOV}$

30 NOV

20 NOV
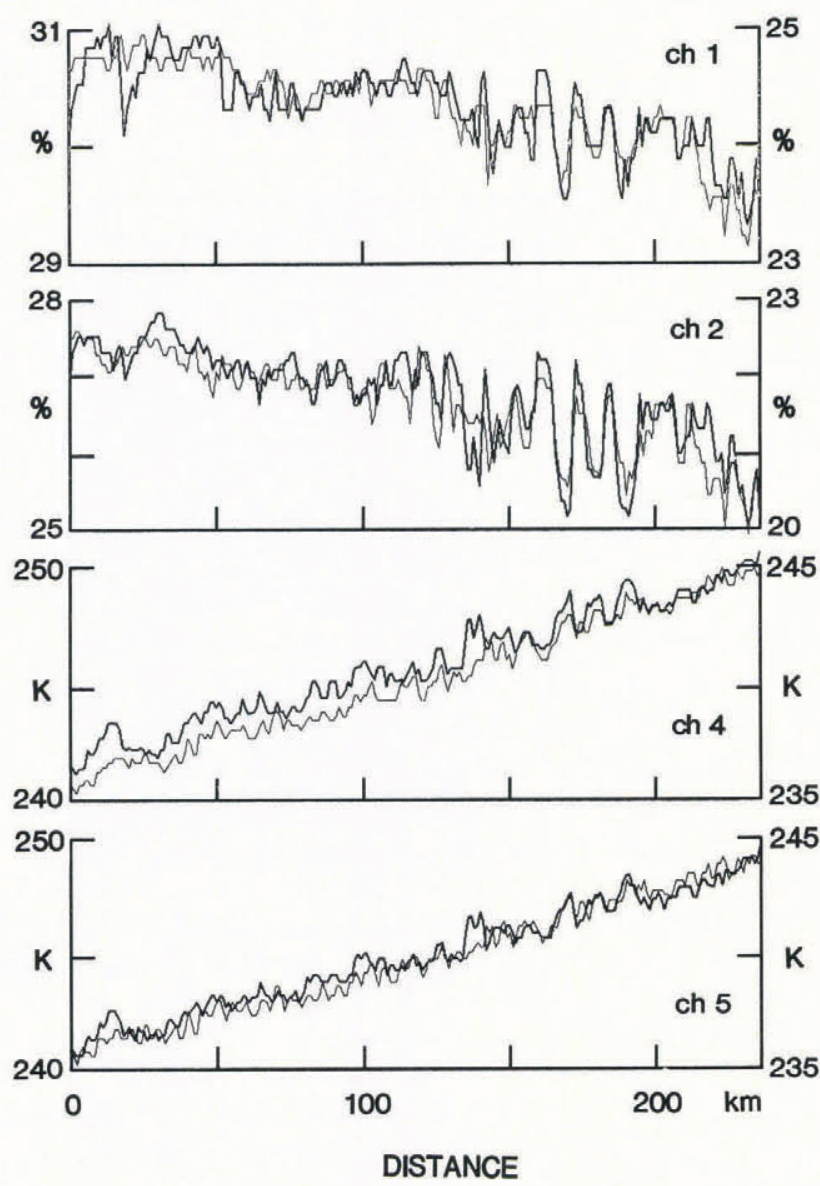

Fig.5. NOAA-7 AVHRR data from channels 1, 2, 4, and 5 along the study line on 20 and 30 November 1984.

surface conditions based on ground observation. Fig.6 shows the AVHRR data and distribution of the area where a glazed surface exceeds $70 \%$. The glazed surface zone is hatched in Fig.6.

Since the satellite data for both 20 and 30 November have a similar variation along the study line but a larger amplitude in the variation of each channel on 30 November than on 20 November, the data for 30 November are chosen for discussion. Reflected radiance from channel 2 is given at the top of the figure because the variation is larger than that for channel 1. For brightness temperatures, channel 4 data are used because of the lower effect of atmospheric vapour content in comparison with channel 5 .

Comparing the reflected radiance from channel 2 with the relative surface temperature, given as the deviation from the linear relation between surface temperatures and altitudes to eliminate the effect of the surface profile on the surface temperature, they have a high negative correlation. As the lower albedo zone coincides with the higher surface-temperature zone, the lower albedo is not due to the shadow of the surface relief but due to surface conditions. Fig.7 indicates the relationship between altitude and surface temperature (T4) for glazed and snow surfaces where each surface has an area greater than $90 \%$ along the study line. The surface temperature is about $0.5^{\circ} \mathrm{K}$ higher for a glazed surface composed of a multi-layered ice crust than for a snow surface, probably because of the difference in the thermal (or radiative) property of these surfaces, as was suggested by Mae and others (1981).

Since the albedo of bare ice is lower than that of snow, and particularly low in the near infra-red region (channel 2), the ratio of channel $2 /$ channel 1 should be lower at the surface with properties more similar to those

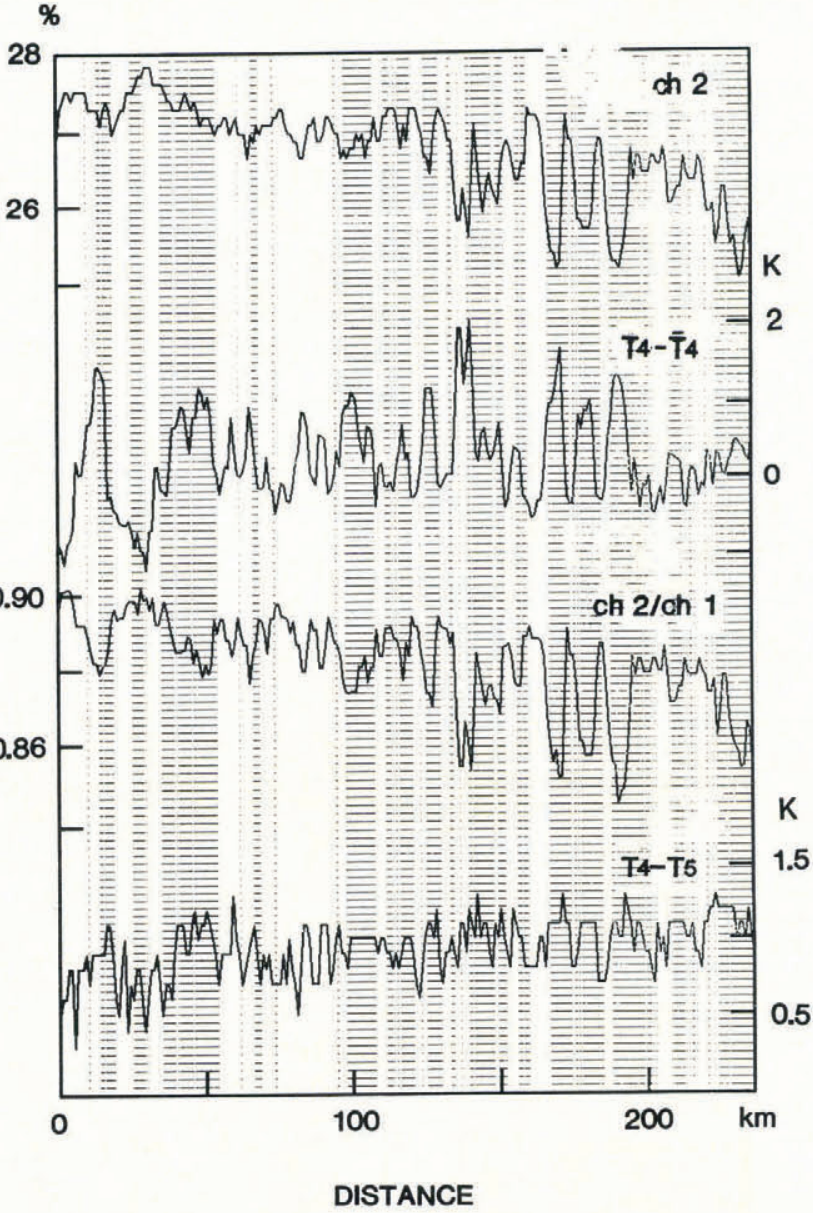

Fig.6. Comparison of NOAA-7 AVHRR data along the study line on 30 November, with the distribution of the glazed surface zone shown as the hatched areas.

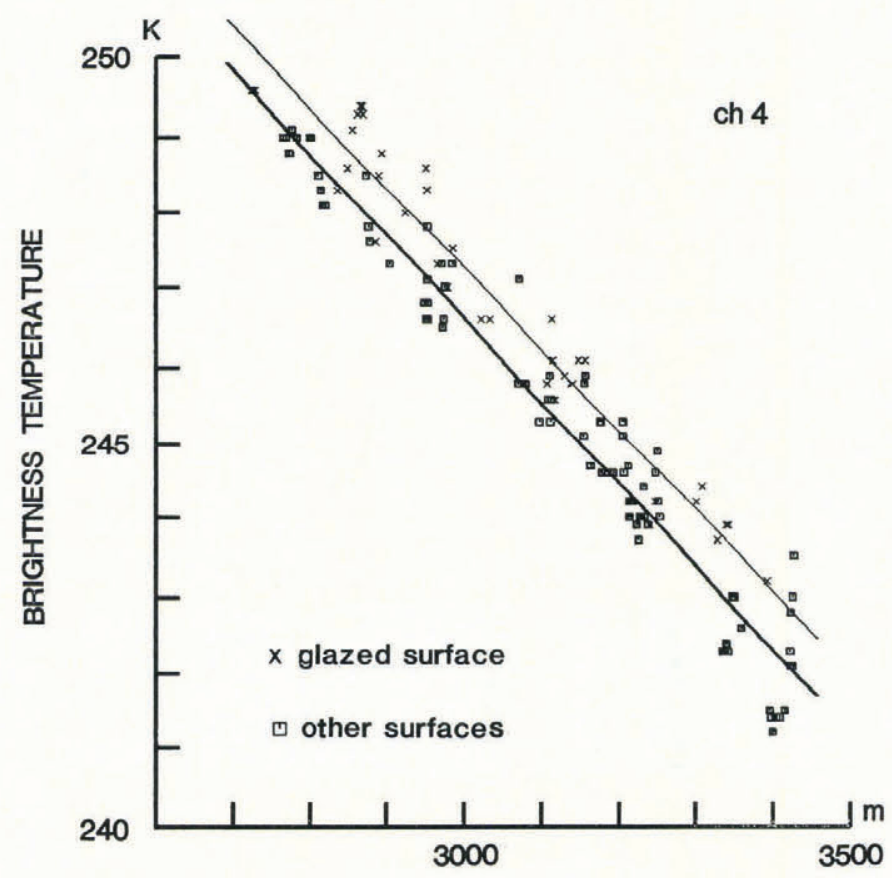

\section{ALTITUDE}

Fig.7. Relationship between altitudes and surface temperatures, T4, for glazed and snow surfaces along the study line. 
of ice. As is shown in Fig.6, both channel 2/channel 1 and the albedo of channel 2 show a high positive correlation. This suggests that variations in the ratio of channel $2 /$ channel 1 and the albedo of channel 2 depend on surface conditions such as snow or ice crust (properties more similar to those of ice).

Furthermore, as the difference in emissivity between channels 4 and 5 increases with increasing grain-size (Dozier and Warren 1982), the temperature difference between channels 4 and 5 given in the bottom of the figure should be larger for the ice crust of a glazed surface than on snow. Fig.6 shows a good negative correlation between T4-T5 and the channel 2 albedo. This may suggest that the temperature difference (T4-T5) along the study line depends on surface conditions such as snow or ice crust.

The NOAA AVHRR data are compared with the distribution of the glazed surface zone shown as hatched in Fig.6. Having taken the accuracy of the map projection of AVHRR imagery into account, it can be said that the variations of the AVHRR data are well related to the distribution of glazed surfaces. That is, the part with a lower albedo, higher surface temperature, lower ratio of channel $2 /$ channel 1 , and larger T4-T5 coincides with the area where a glazed surface develops. Therefore, the imagery of channel 2 of AVHRR shown in Fig. 4 can be interpreted as follows. The relatively dark mottled parts indicate a glazed surface and the black-and-white parts (except the edges) indicate a bare ice (or rock) and snow surface.

The good correlation between NOAA AVHRR data and the distribution of glazed surfaces may be explained by the fact that a glazed surface is composed of a multi-layered ice crust, as shown in Fig.2, and the radiative and thermal properties of a glazed surface are closer to those of ice than snow.

\section{CONCLUSIONS}

The present study shows that with NOAA AVHRR data it is possible to distinguish bare ice, glazed surfaces, and snow on the Antarctic ice-sheet surface. This approach can therefore be applied to the surface mass and heat balance of the Antarctic ice sheet where they depend solely on surface conditions.

\section{ACKNOWLEDGEMENTS}

The authors wish to express their thanks to Professor Takeo Hirasawa of the National Institute of Polar Research, leader of the 25th Japanese Antarctic Research Expedition, and its members for receiving satellite data and supporting the field observations. Professor Atsumu Ohmura and Dr Konrad Steffen of the Department of Geography, Swiss Federal Institute of Technology, made valuable comments on the original manuscript. All computations were carried out at the Information Processing Center, National Institute of Polar Research.

\section{REFERENCES}

Dozier J, Warren S G 1982 Effect of viewing angle on the infrared brightness temperature of snow. Water Resources Research 18(5): 1424-1434

Dozier J, Schneider S R, McGinnis D F Jr 1981 Effect of grain size and snowpack water equivalence on visible and near-infrared satellite observations of snow. Water Resources Research 17(4): 1213-1221

Fujii Y, Kusunoki K 1982 The role of sublimation and condensation in the formation of ice sheet surface at Mizuho Station, Antarctica. Journal of Geophysical Research 87(C6): 4293-4300

Mae S, Yamanouchi T, Wada M 1981 The measurement of the surface temperature at Mizuho Station, East Antarctica. Memoirs of National Institute of Polar Research. Special Issue 19: 40-48

Warren S G 1982 Optical properties of snow. Reviews of Geophysics and Space Physics 20(1): 67-89

Watanabe O 1978 Distribution of surface features of snow cover in Mizuho Plateau. Memoirs of National Institute of Polar Research. Special Issue 7: 44-62 